\title{
THE EDTECH BLOG: LEARNING BEYOND THE CLASSROOM THROUGH SOCIAL SPACES FOR INFORMAL LEARNING
}

\author{
Joseph Rene Corbeil, The University of Texas Rio Grande Valley, rene.corbeil@utrgv.edu \\ Maria Elena Corbeil, The University of Texas Rio Grande Valley, mariaelena.corbeil@utrgv.edu
}

\begin{abstract}
Thirteen years ago, the EdTech Blog was created as an informal learning space to promote a professional community of learners enrolled in a fully online graduate program. The blog was created to enable current and former EdTech students to discuss contemporary topics and issues related to the profession. This paper will provide: an overview of the literature on social spaces for informal learning; a brief history and description of the EdTech blog, its purpose and goals, and how it was implemented; and the results of phase one of a formative evaluation where students weighed in on the blog's goals and impact.
\end{abstract}

Keywords: Social Learning, Informal Learning, Social Media, Blog

\section{INTRODUCTION}

This October marks the 13th anniversary of the EdTech Blog. The blog was created in 2005 as an informal learning space to enable online students to interact with other members of their cohort to discuss contemporary topics and issues related to their field of study.

The EdTech Blog is unique in that it crosses programs, geography, and time. Students join the online community in their first course and remain engaged until they graduate. Some students choose to follow the conversations after graduation and it is not uncommon for graduates to chime in on issues that are important to them.

While educational blogging has existed for almost as long as blogs themselves, aside from a few examples in the literature of semester-long multi-course blogging experiments, we have yet to find another sustained case of blogging that unites students and graduates from different courses and across multiple programs through weekly discussions of current topics and issues related to their profession.

The goals for the creation of the EdTech Blog were twofold:

- Create an informal environment where groups of learners could discuss and debate emerging issues in their field.

- Cultivate a culture of professionalism to transform learners into informed educational technology professionals.

These goals align with the Educational Technology master's and doctoral program goals and professional standards for Educational Technology practitioners as defined by the Association for Educational Communications and Technology (AECT). Graduates of these programs are expected to demonstrate leadership and continued improvement of professional practice in the field of Educational Technology.

By facilitating the discussion of contemporary topics and issues related to the profession on a weekly basis throughout students' academic programs, the EdTech Blog enables students to become familiar with, and do research on, the emerging challenges and issues in their intended profession. More specifically, the EdTech Blog helps students to develop the following AECT professional competencies and dispositions (AECT Standards, 2012): 


\section{Issues in Information Systems \\ Volume 18, Issue 4, pp. 57-64, 2017}

- demonstrate foundational knowledge of the contribution of research to the past and current theory of educational communications and technology (p. 3)

- explore, evaluate, synthesize, and apply methods of inquiry to enhance learning and improve performance (p. 3)

- $\quad$ apply research methodologies to solve problems and enhance practice (p. 3)

- apply formal inquiry strategies in assessing and evaluating processes and resources for learning and performance

(p. 3)

- demonstrate an inquiry process that assesses the adequacy of learning and evaluates the instruction and implementation of educational technologies and processes grounded in reflective practice (p. 1)

After 13 years of continuous operation, it was time to evaluate the blog's goals and students' perceptions regarding its impact.

\section{REVIEW OF LITERATURE}

Today, higher education institutions are facing challenges, including the rising cost of higher education; competition from online, for-profit, and specialized schools (Sommer, 2014); the public and business sector demand for graduates with twenty-first century skills; the growing number and diversity of the student population; the way the global movement has changed the way people work and learn (Luna Scott, 2015); and the need to transform instructional methods and integrate technology to meet these demands. McDaniel (2014) noted that today's learners are more challenging because they possess a wider range of "skills, interests, and learning preferences" (p. 1). As a result, students increasingly report preferring to engage in both formal and informal learning experiences, experiential activities, and collaborate with others (McDaniel, 2014). They also expect more from their educational experiences, such as being able to build networks of knowledge and professional connections. The good news for higher education, according to Horrigan (2016), is that although "digital technology plays a notable role in these knowledge pursuits...place-based learning remains vital to many" (para. 1). The next section provides an overview of the literature on informal learning and how social media can be harnessed to integrate informal learning in formal education spaces.

\section{Social Spaces for Informal Learning}

Definitions of formal and informal learning abound. According to Scott, Sorokti, and Merrell (2016), formal learning usually leads to a degree or credentials of some kind. It is developed by experts with specific objectives and activities facilitated in educational institutions. The work of the European Commission on formal learning adds that in this model, learners are highly aware of their learning as they participate intentionally (as cited in Peeters, et al., 2014). On the other hand, in informal learning, it is the learner who usually identifies and leads the activities that occur outside of a formal institution (Scott, Sorokti, \& Merrell, 2016). Also, since objectives and assessments do not drive the learning as they do in formal educational environments, this flexibility allows for "time and space...given for exploration, experimentation, developing interests, and intrinsic motivations" (Hung, Lee, \& Lim, 2012, p. 1072). The European Commission (as cited in Peeters, et al., 2014, p. 182) adds that this type of learning is naturally occurring so learners may not even be aware that it is happening.

Although informal learning is oftentimes defined as learner initiated and unstructured, Peeters, et al., (2014) note that "some authors...prefer...stressing a continuum rather than distinct categories with each its own characteristics" (p. 182). In this light, the EdTech Blog described in this study, contrary to the more commonly accepted definitions of informal learning, provides some structure to help initiate, facilitate, and maintain an ongoing discussion between different groups of learners and graduates. This categorizes it as a different kind of informal learning like the one identified by Eaton (2010) as non-formal learning. She notes that unlike informal learning, its non-formal counterpart is led by a more experienced person in an environment designed with some structure, and although a formal credential is usually not attained, "non-formal education is highly enriching and builds an individual's skills and capacities" (para. 3). Non-formal learning is also oftentimes viewed as more motivating, as it capitalizes on the learners' interests, thus encouraging their ongoing participation (Eaton, 2010). Sevdalis and Skoumious (2015) also underscore its value, 


\section{Issues in Information Systems \\ Volume 18, Issue 4, pp. 57-64, 2017}

citing research that found it positively influenced teaching, as well as the students' regard for the topic and their motivation to pursue further learning.

\section{The Role of Social Media in Informal Learning}

Hung, Lee, and Lim (2012) observe that today, social media is reminiscent of how learning was facilitated informally before the advent of formal education. They added, what is different today is that social technologies allow members of communities in geographically distinct areas to come together to pursue mutual interests and goals in ways that were not possible before. Chunngam, Chanchalor, and Murphy (2014) note, "while informal learning itself has a centuries-old tradition, it has only recently been able to benefit from the support of powerful information and communication technologies (ICTs)" (p. 863). For example, studies reviewed by Scott, Sorokti, and Merrell (2016, p. 78) suggest that when learners in formal learning environments are given the opportunity to use technology to collaborate outside of the learning management system, they are able to build a community in which they can "aggregate and share resources, participate in collective knowledge generation, and manage their own meaning making." The technology tools available today put the construction and sharing of topic-specific knowledge at the learners' fingertips.

The learning stems from the interactions in which learners are able to "offer sophisticated and critical interpretations and analysis of the world, their own work and the work of others" (Costa, Cuzzocrea, \& Nuzzaci, 2014, p. 164). This community results in a professional network that lasts beyond the time and space of the class. It is not uncommon to see these academic relationships transform into long-lasting professional opportunities and even personal friendships. This "lends support to the idea that properly designed social technologies can increase the potential for members to expand their networks beyond typical boundaries and receive something of value from doing so" (Scott, Sorokti, \& Merrell, 2016, p. 78). As a result, according to Peeters, et al., (2014), more educators are becoming aware of the value of using informal learning to complement the learning strategies and activities of higher education.

The question then is, how do designers and faculty of online courses and programs in formal higher education environments integrate informal opportunities to meet the academic and professional needs of current and up-andcoming professionals?

\section{THE EDTECH BLOG}

Although there is vast research on the uses and benefits of informal learning and the growing number of technologies to facilitate it, none, that we have been able to find in the research literature, parallels the scope and longevity of the EdTech Blog. The EdTech Blog is a multi-course, cross-program platform that enables students to engage in discussions of discipline-specific problems and issues taken straight from today's headlines. The blog is unique in that it exists between formal and informal learning spaces and crosses programs, geography, and time. Students join the online community in the first semester of the master's or doctoral program and remain engaged until they graduate. Some students choose to follow the conversations after graduation and it is not uncommon for them to chime in on issues that are important to them.

The EdTech Blog was born out of a need to provide students in a fully online graduate program a friendly and inviting space to socialize and interact with other members of their cohort. The Master of Education in Educational Technology went fully online in 1998, and at the time, broadband Internet access was not widely available and informal communication options were very limited.

Although the early learning management systems had discussion forums, the user interfaces were cumbersome and unfriendly to use. They also did not facilitate communication with members outside the course, thereby cocooning students within their courses. Thus, establishing and maintaining social presence and a sense of community within a cohort of online learners was challenging. Unsurprisingly, our online students tended to feel more isolated than their on-campus counterparts, resulting in lower student satisfaction and higher dropout rates. 


\section{Issues in Information Systems \\ Volume 18, Issue 4, pp. 57-64, 2017}

By 2005, social media was still in its infancy. Facebook and Twitter were newcomers, so there weren't many places for online students to socialize. It was in this context that, on October 16, 2005, the EdTech Blog was born. Since then, there have been 445 posts accompanied by 13,490 student comments. Over time, participation expanded to students from other cohorts, and when the doctoral specialization in Educational Technology went online in 2011, the invitation was extended to doctoral students as well.

Each week, a faculty member posts an Educational Technology related article taken directly from the headlines. News stories are carefully selected to bring into focus emerging trends and issues within the discipline. Each article includes a prompt to focus the discussion and get students thinking about a specific aspect related to the issue. The prompts are designed to engage students in discussions at the higher levels of Bloom's Taxonomy (analysis, synthesis, or evaluation) and promote community building, elicit reflection, and promote student leadership.

A link to the blog is then posted to the weekly announcement page of each course, with an invitation for students to submit their views to the topic at hand. To incentivize students to participate, contributions to the EdTech Blog can be applied toward students' overall class participation points. With multiple options for class participation, including participation in the class discussion forums and attending voluntary synchronous sessions, students can choose not to participate without negatively impacting their overall end-of-course grade.

To our pleasant surprise, participation in the blog discussions took off and student involvement has remained high ever since.

\section{EDTECH BLOG PROGRAM EVALUATION}

The Educational Technology faculty have engaged in continuous evaluations of their academic programs since their inception. Some program evaluations were performed to assess learning outcomes and ensure alignment of key assessments to professional standards for regional and national accreditation. Other evaluations were initiated to assess program effectiveness and efficiency for the purpose of program improvement. Yet, until very recently, the EdTech Blog has by and large escaped deeper scrutiny. Due in part, to its existence between formal and informal learning spaces, it was not considered to be part of any academic program.

Hence, after almost 13 years of continuous operation, it was time to take a closer look at the EdTech Blog's goals, impact, processes, and outcomes. In Phase I, the students were asked to assess their thoughts, opinions, and feelings regarding the blog's goals and impact. In Phase II, the EdTech Blog's processes and outcomes will be assessed to evaluate their effectiveness as an informal learning space for helping students to grow content knowledge, leadership skills, and professional dispositions, as well as to identify challenges, and successful strategies, associated with the EdTech Blog's implementation.

\section{Phase I Evaluation: Evaluating Goals and Impact}

To launch the Phase I evaluation, on April 23, 2017, an article describing the history and goals of the EdTech Blog was posted to the blog. Students were asked to read the article and to reflect on the following two questions:

1. To what extent do you believe the EdTech Blog is achieving its goals?

2. Has participation in the EdTech Blog impacted you academically and/or professionally?

Fifty-eight students from the Master of Education in Educational Technology and the Doctor of Education with a Specialization in Educational Technology chose to participate in the discussion. This accounts for $91 \%$ of the entire M.Ed. and Ed.D. Educational Technology student population for that semester. The next section summarizes the outcome of the Phase I survey.

Regarding the first question, To what extent do you believe the EdTech Blog is achieving its goals?, students overwhelmingly agreed that it was achieving its goals. The following statements, grouped by goal, are a representative sampling of the comments that were posted in response to this question. 
Goal 1: Create an informal environment where groups of learners could discuss and debate emerging issues in their field.

What I really like about the EdTech blog is that it is the main mechanism where I can see what other EdTech students are thinking across multiple years and classes. That's a unique opportunity I really appreciate. While occasionally communities arise within a given semester, as a group project gets worked on, too often those people drift out of any peer-to-peer discussion orbit. So this blog helps with that. Also, Ifeel that many of the articles were useful in highlighting an aspect of EdTech I hadn't considered before.

I have really enjoyed the articles and discussions. The articles that are chosen always seem to be relevant to what I am currently working on. The discussions have helped me to consider multiple aspects of an emerging issue.

I have learned to appreciate the EdTech Blog. Each week I get to contribute to a larger conversation on a topic I may not have stopped to consider. It's interesting to stop and process something that is beyond my own purview. This blog is an extension to the learning that occurs within the program.

I have learned about new and relevant topics, read others' perspectives on those topics, and had multiple opportunities to contribute. Because we know each other from current and former classes, the EdTech Blog feels like a space where we can speak our minds professionally, respecting all opinions.

Academically, I prefer reading short and interesting articles over the somewhat dry chapters in textbooks. The articles and discussions in the EdTech Blog are always interesting and I can take meaning from each post and apply it to my teaching.

I think the blog is a great way to stay current on emerging Educational Technology topics and issues. The EdTech Blog gives students a place to share their ideas, feelings, and knowledge on a multitude of topics over a sustained period of time. Sometimes we learn best from others.

Goal 2: Cultivate a culture of professionalism to transform learners into informed Educational Technology professionals.

I have greatly appreciated and benefited from being a part of the EdTech Blog community over the last 3 years of my doctoral program. It has helped me to develop my expression skills and has opened my mind to consider multiple viewpoints. I believe the blog is achieving its goals and I can see advancements coming. I really appreciated last week's blog post because it was so interactive. Many of my friends and I have discussed the subject outside of the blog, so I think it was highly effective.

When I first started the program, I was a bit apprehensive about having to post my thoughts to an online public blog, but after a few semesters I have gained an appreciation for the blog. First, I have learned a lot of practical information each week from the article readings. I also have learned a lot about my own perspectives on education, and have gained insight from my peers. The new information has prompted me to change my teaching for the better. Overall, I would say that the blog is very beneficial.

The blog is a great way to keep ourselves up to date on latest research and findings related to technology and education. I like the blog because it allows us to voice our opinions and maybe help someone along the way.

I firmly believe that as aspiring Educational Technologists, we must read, read, and read! We need to know our profession inside and out! I truly enjoy reading the articles and the comments from individuals in the profession of technology and education.

I personally have learned a lot from this blog throughout the years. The EdTech Blog promotes professional and technical writing in an informal, yet professional environment. This form of communication is important 
in the workplace and my hope is that this blog will continue for many years to come. I am beginning to feel disheartened that I am approaching the end of my program, but I am sure I'll still chime in from time to time.

Regarding the second question, Has participation in the EdTech Blog impacted you academically and/or professionally?, students cited multiple ways the EdTech Blog had positively impacted them. The following statements are a representative sampling of the comments that were posted in response to this question.

With my hectic schedule, I would not be able to keep up with the latest news or trends in the field without some reinforcement from the articles posted in the blog. The articles and pursuant discussions have allowed me to grow both academically as a student and professionally as a future Educational Technologist. Each week, I am tasked to read an informational source, contemplate its meaning, put my thoughts and opinions into words, and defend my stances with factual and/or experiential evidence. I believe that in any profession, one needs to assume a philosophy of lifelong learning. The EdTech Blog serves to encourage this mindset in its users and has managed to sustain a following all these years.

To be completely honest, I'm surprised this question is even being asked. I have benefited both academically and professionally from this blog. Not only have I been able to use it to connect to the relevant topics I'm covering in my classes, it has helped me develop a more professional approach in my work as a Campus Technologist...Many of the topics addressed in this blog have real life implications at work...Although it is a requirement for some of my classes, it is an activity I eagerly await and is one of the first assignments I complete each week.

The EdTech Blog is very relevant to me, both academically and professionally. It amazes me how each article, no matter what class I am taking, is meaningful to what I am currently learning. It has been very beneficial to share what I have just learned through a discussion with others. Professionally, I have been able to see how educators from multiple settings are using technology to create the school of the future. I have enjoyed being a part of this community and knowing that my input may be able to impact others in a similar way.

I have the EdTech Blog bookmarked and plan to continue to reference it even after I've obtained my degree. I like that the blog highlights articles that deal with all grade levels as I can often find information that deals with my specific interests. I have already used some of the tidbits I've gleaned from these articles in my classroom and look forward to learning more things that I can apply to aid my students' learning.

\section{Phase II Evaluation: Evaluating Processes and Outcomes}

Phase I examined the EdTech Blog's goals and impact from the learners' perspective. In Phase II, the processes and outcomes of the EdTech Blog will be assessed. This more extensive evaluation will begin in Fall 2017, and continue through Spring 2019.

Process evaluation, which focuses on implementation, will be used to determine if the strategies pertaining to the facilitation of the EdTech Blog are implemented as planned and if they achieve their goals. The outcome of the process evaluation will be to illustrate how to replicate a multi-course, cross-program blog to establish an informal learning space that promotes social learning.

Outcomes evaluation, which focuses on measuring changes in understanding, attitudes, behaviors, and practices, will analyze participants' understanding of content knowledge and professional skills development resulting from their prolonged participation in the EdTech Blog community. Outcomes evaluation will help program faculty determine if sustained participation in the EdTech Blog contributes to the development of a culture of professionalism that transforms learners into informed Educational Technology professionals. 


\section{SUMMARY}

The results of a recent Pew Research Center Survey (Horrigan, 2016) bring good news to higher education, as it reveals that "America is nation of ongoing learners" (para. 3), which means there are ample opportunities for providing formal, informal, and non-formal learning options to an increasing number of learners. Yet, how we provide those learning experiences is rapidly changing.

Bickford and Wright (n.d.) observe that for higher education, it is a "new era." They cite Boyer and Mitgang's (n.d.) call for "places that foster connections rather than compartmentalization" (Spaces for Learning in Community, para. 1). Consequently, "research supports the value of looking at the interplay of formal and informal learning spaces in online learning environments" (Scott, Sorokti, \& Merrell, 2016, p. 77), and "both types of learning are considered to interact and overlap" (Peeters, et al., 2014, p. 182). As a result, the EdTech Blog was started as a response for the need to support the Educational Technology program goals to: create a space where students can discuss and debate emerging issues in their field; produce informed Educational Technology professionals; and cultivate a culture of professionalism and leadership.

Based on students' responses from the Phase I evaluation, the EdTech Blog appears to be achieving its intended goals and is positively impacting students, both academically and professionally. The Phase II evaluation on processes and outcomes will analyze participants' understanding of content knowledge and professional skills development resulting from their prolonged participation in informal learning communities and illustrate to interested academicians how to replicate a similar multi-course, cross-program, social learning space for their online programs. With 13 years of data from news articles and dialog, the EdTech Blog is a rich resource for tracking Educational Technology trends over the past decade. Future research can also focus on analyzing past trends to identify future directions in Educational Technology research.

\section{REFERENCES}

AECT Standards (2012). Association for Educational Communications for Technology. Retrieved from https://c.ymcdn.com/sites/aect.site-ym.com/resource/resmgr/AECT_Documents/AECTstandards2012.pdf

Bickford, D. J., \& Wright, D. J. (n.d.). Chapter 4. Community: The hidden context for learning. Retrieved from https://www.educause.edu/research-and-publications/books/learning-spaces/chapter-4-community-hiddencontext-learning

Chunngam, B., Chanchalor, S., \& Murphy, E. (2014). Membership, participation and knowledge building in virtual communities for informal learning. British Journal of Educational Technology, 45(5), 863-879. doi:10.1111/bjet.12114

Costa, S., Cuzzocrea, F., \& Nuzzaci, A. (2014). Uses of the Internet in educative informal contexts: Implication for formal education. Comunicar, XXII(43), 163-171.

Eaton, S. E. (2010). Formal, non-formal and informal learning: What are the differences? Retrieved from https://drsaraheaton.wordpress.com/2010/12/31/formal-non-formal-and-informal-learning-what-are-thedifferences

Horrigan, J. B. (2016, March 22). Lifelong learning and technology. Retrieved from http://www.pewinternet.org/2016/03/22/lifelong-learning-and-technology

Hung, D., Lee, S., \& Lim, K. Y. (2012). Authenticity in learning for the twenty-first century: Bridging the formal and the informal. Educational Technology Research and Development, 60(6), 1071-1091. doi:10.1007/s11423-012-9272-3 
Luna Scott, C. (2015, December). The futures of learning 3: What kind of pedagogies for the 21st century. Retrieved from http://unesdoc.unesco.org/images/0024/002431/243126e.pdf

McDaniel, S. (2014). Every space is a learning space: Encouraging informal learning and collaboration in higher education environments. BWBR Knowledge Series, 1-8. Retrieved from http://unesdoc.unesco.org/images/0024/002431/243126e.pdf

Peeters, J., Backer, F. D., Buffel, T., Kindekens, A., Struyven, K., Zhu, C., \& Lombaerts, K. (2014). Adult learners' informal learning experiences in formal education setting. Journal of Adult Development, 21(3), 181-192. doi:10.1007/s10804-014-9190-1

Scott, K. S., Sorokti, K. H., \& Merrell, J. D. (2016). Learning "beyond the classroom" within an enterprise social network system. The Internet and Higher Education, 29, 75-90. doi:10.1016/j.iheduc.2015.12.005

Sevdalis, C., \& Skoumious, M. (2015). Teachers' conceptions about the implementation of non-formal science education programs. International Journal of Science in Society, 7(4), 19-30.

Sommer, D. (2014). Five trends impacting competition in today's higher ed marketplace. Retrieved from http://evolllution.com/opinions/trends-impacting-competition-todays-higher-ed-marketplace 